\title{
FAKTOR-FAKTOR YANG MEMPENGARUHI KEPATUHAN WAJIB PAJAK DALAM MEMBAYAR PAJAK UMKM
}

\author{
Oleh: \\ Rinaldi Zentira Fikri ${ }^{1}$ \\ Mourris Sagara ${ }^{2}$ \\ Didin Hadi Saputra ${ }^{3}$ \\ Nasuhi $^{4}$ \\ Program Studi Administrasi Publik ${ }^{1,3,4}$, Jurusan Administrasi Bisnis ${ }^{2}$ \\ Fakultas llmu Administrasi, Universitas Nahdlatul Wathan Mataram \\ Email: \\ aldyz561@ gmail.com ${ }^{1}$ \\ didinimarc@gmail.com ${ }^{3}$
}

\begin{abstract}
ABSTRAK
Penelitian ini bertujuan untuk menguji pengaruh kesadaran wajib pajak, pengetahuan dan pemahaman, sanksi terhadap kepatuhan wajib pajak UMKM. Sampel penelitian ini sebanyak 80 responden yang merupakan pemilik usaha mikro kecil menengah yang berada di Kecamatan Suralaga Kabupaten Lombok Timur. Hasil penelitian dari penelitian ini dikumpulkan melalui kuesioner yang diproses dan analisis dengan menggunakan uji t. Metode yang digunakan dalam penentuan sampel penelitian ini adalah dengan menggunakan Purposive Sampling. Uji kualitas data yang digunakan dalam penelitian ini adalah uji validitas pearson correlation dan uji reliabilitas menggunakan cronbach alpha. Untuk uji hipotesis dalam penelitian ini menggunakan uji t. Hasil penelitian ini menunjukkan bahwa semua variabel berpengaruh secara signifikan seperti kesadaran wajib pajak, pengetahuan dan pemahaman, sanksi pajak berpengaruh terhadap kepatuhan wajib pajak.
\end{abstract}

Kata Kunci: kesadaran wajib pajak, pengetahuan, pemahaman, sanksi, kepatuhan, pajak 


\begin{abstract}
This study aims to examine the effect of taxpayer awareness, knowledge and understanding, and sanctions on MSME taxpayer compliance. The sample of this study was 80 respondents who were owners of micro, small and medium enterprises in Suralaga District, East Lombok Regency. The research results of this study were collected through a questionnaire which was processed and analyzed using the $t$ test. The method used in determining the sample of this study is to use purposive sampling. The data quality test used in this study was the validity test of the Pearson correlation and the reliability test using Cronbach alpha. To test the hypothesis in this study using the t test. The results of this study indicate that all variabels have a significant effect such as taxpayer awareness, knowledge and understanding, tax sanctions have an effect on taxpayer compliance.
\end{abstract}

Keywords: compliance, knowledge, sanctions, taxes, taxpayer awareness, understanding

\title{
A. PENDAHULUAN
}

Pajak secara umum adalah pungutan atau iuran kepada masyarakat yang dilakukan oleh negara, bersifat memaksa, serta telah diatur oleh Undang Undang. Pajak tersebut dapat dipungut secara langsung serta bukan merupakan "pungli" atau pungutan liar, hasil pungutan yang telah didapat akan digunakan untuk membiayai pembangunan negara, baik di pusat maupun di daerah. (Sumarsan, 2015) Di Indonesia, pajak merupakan salah satu sumber penerimaan utama, karena sumber utama inilah segalam macam bentuk pajak (termasuk pajak UMKM) dipungut serta di manfaatkan untuk kesejahteraan rakyat. Di Indonesia juga, lebih dari $70 \%$ dari $100 \%$ sumber dari seluruh pendapatan negara bersumber dari pajak, sisanya dari $70 \%$ itu bersumber dari bea dan cukai, PNBP atau Penerimaan Negara Bukan Pajak atau PNBP, serta sumber penerimaan negara selain dari pajak yang sah, dengan kata lain, pajak di negara ini masih menjadi tumpuan utama pembangunan di segala sisi dan segala sektor (Prameswari, 2019).

Sumber pendapatan negara di Indonesia berasal dari beberapa sisi, salah satunya dari pajak UMKM, Non Pajak dan Hibah. Tiga sumber inilah yang menjadi penopang penerimaan kas negara. Sumber pendapatan negara nantinya akan digunakan untuk membangun fasilitas dan infrastruktur umum dan juga akan kembali lagi untuk rakyat dalam program bantuan guna menyejahterakan rakyat (Aliffia, 2019).

Negara menggunakan penerimaaan pajak untuk menopang pembangunan, negara juga memiliki target atau tujuan, bahwa peningkatan pemungutan pajak ke masyarakat akan tercapai jika muncul peningkatan atau pertumbuhan jumlah Wajib Pajak baru. Segala macam ikhtiar mengoptimalkan berbagai macam sumber penerimaan pajak tidak mungkin hanya berfokus pada peran Dirjen Pajak, tetapi dibutuhkan juga peran para wajib pajak itu sendiri (Huda et al., 2016).

Besarnya peran serta fungsi pajak untuk menggerakkan sistem dan roda perekonomian serta proses pembangunan, pemerintah telah terus menerus secara berkelanjutan melakukan pembangunan, baik itu melalui perubahan sistem agar 
terus menerus menjadi lebih baik, ataupun dengan cara perubahan atau reformasi dari sisi yang lain (Mory, 2015)

Salah satu dari sekian banyak perubahan peraturan atau regulasi dari perpajakan tersebut adalah melakukan perubahan peraturan per UndangUndangan dalam hal perpajakan, tujuannya agar lebih profesional serta akuntabel. Dari perubahan tersebut, maka muncullah aturan tentang self assesment system, yaitu salah satu ikhtiar yang dilaksanakan oleh pemerintah dalam bidang perpajakan serta melakukan reformasi atau perubahan dalam bidang perpajakan itu sendiri, atau peraturan tentang pemberian wewenang serta amanah kepada pengusaha kena pajak atau PKP untuk membayar sendiri serta melaporkan besarnya pajak yang terutang dan harus dibayar oleh WP atau wajib pajak itu sendiri. Sistem memungut serta menghitung sendiri pajak adalah sistem yang terapkan oleh pemerintah kepada wajib pajak dalam menghitung sendiri pajaknya yang akan dibayarkan ke negara (Sumarsan, 2015). Dengan demikian, penerimaan pajak sangat bergantung kepada kedisiplinan para wajib pajak (WP) dalam membayar pajak.

Salah satu faktor yang menyebabkan rendahnya Tax Ratio pajak di Indonesia adalah rendahnya pendapatan perkapita masyarakat kita, seta tingkat kepatuhan para ajib pajak kita yang masih rendah, baik itu wajib pajak yang pengahasilannya besar maupun kecil belum dilakukan dengan tranapara dan akuntable. Faktor rendahnya kesadaran masyarakat dalam menghitung sendiri, melaporkan operasioanl dari usahanya tersebut. Faktor tersebut juga karena disebabkan oleh ketidak tahuan masyarakat tentang aturan atau ketentuan umum dan tata cara perpajakan atau KUP. Persoalan tingkat kepatuhan atau tingakat kedisplinan wajib pajak dalam melaporkan pajaknya terus menerus terkadi dalam dunia oerjaka di Indonesia di Indonesia (Yadnyana \& Sudiksa, 2011). Permasalahan tingkat kepatuhan wajib pajak menjadi permasalahan yang terus-menerus terjadi dalam bidang perpajakan. Di Indonesia juga tingkat kepatuhan wajib pajak masih rendah. Rendahya tingkat kepatuhan wajib pajak memenuhi kewajiban perpajakannya masih sangat ironis jika dibandingkan dengan tingkat pertumbuhan usaha di Indonesia (Yusro \& Kiswanto, 2014).

\section{UMKM}

Pertumbuhan serta peningkatan jumlah para pengusaha Mikro, Kecil dan Menengah (UMKM) di Indonesia mengalami kenaikan dari tahun ke tahun. Kenaikan tersebut meningkatkan dan memberi "signal" bahwa kesadaran masyarakat kita secara umum mampu memberikan harapan bahwa masyarakat Indonesia secara umum memahami dan telah mengerti bahwa solusi untuk menjadi negara maju dengan pertumbuhan para pelaku UMKM perlahan telah menunjukka tren yang positif. Namun, dampak dari kenaikan ribuan jumlah UMKM tersebut tidak diimbangi tidak diikuti dengan dengan kesadaran yang tinggi oleh para pemilik UMKM untuk dapat melaksanakan kewajiban perpajakannya. Di Indonesia, begitu banyaknya jumlah usaha Mikro, Kecil dan Menengah (UMKM) dari tahun ke tahun mengalami peningkatan dan jumlah peningkatannya pun sangat signifikan, hal ini banyaknya usaha Mikro, Kecil dan Menengah (UMKM) (Yusro \& Kiswanto, 2014). 
Dari sekian banyak sumber penerimaan pajak adalah pajak penghasilan orang pribadi yang dibayarkan oleh subjek pajak UMKM (usaha mikro, kecil, menengah) yang peraturan atau regulasinya sudah diatur dalam Peraturan Pemerintah no 46 tahun 2013 (Republik Indonesia \& Syamsudin, 2013), Peraturan ini banyak mengatur tentang tarif PPh Final $1 \%$ yang ditujukan kepada Wajib Pajak pribadi dan badan yang memiliki penghasilan dengan omzet usaha dibawah 4,8 miliar dalam satu tahun. Berdasarkan Undang Undang Nomor 20 tahun 2008 (Mattalatta \& Nugroho, 2017), UMKM adalah usaha produktif milik orang perseorangan dan atau badan usaha yang memenuhi kriteria. Dalam Undang Undang tersebut diatur bahwa para pelaku UMKM diatur secara rinci dan detail mulai dari pemberitahun pajak yang terhutang, proses pencatatan pajak, menghitung pajak yang terutang, serta membayar dan melaporkan pajak yang terutang kepada Direktorat Jendral (Dirjen) Pajak melalui loket loket pembayaran pajak yang sudah tersebar di beberapa tempat, yakni Pos ataupun pihak ketiga yang telah ditunjuk oleh Ditjen pajak.

Untuk memperkuat teori dalam artikel ini, maka disertakan bebrapa teori sebagai berikut, yakni Andriani dalam buku (Seni \& Ratnadi, 2017), dijelaskan bahwa pajak adalah iuran yang dipungut oelh pemerintah keada masyarakat yang dapat dipaksakan dengan berdasarkan Undang Undang dan tidak mendapatkan prestasi kembali serta langsung dapat ditunjuk dan dhasilnya digunakan untuk membiayai seluruh pembangunan di nusantara dan untuk membiayai semua pengeluaran umum yang berhubungan dengan kepentiangan negara dan pemerintahan

Jadi, pengertian di atas dapat disimpulkan bahwa pajak adalah kegiatan memberikan sebagian harta kekayaan masyarakat kepada negara yang bersifat wajib serta serta dapat dipaksakan berdasarkan Undang-Undang yang hasilnya digunakan untuk pembiayaan penyelenggaraan negara dan roda pemrintahan. Sedangkan pajak untuk pelaku atau pelaksanaan UMKM diatur dan tertuang dalam Peraturan Pemerintah (PP) Nomor 23 tahun 2018 tentang Pajak Penghasilan atas Penghasilan dari Usaha yang diterima atau diperoleh oleh Wajib Pajak (WP) (Djaman, 2018).

Sementara aturan turunannya dalam bentuk Peraturan Menteri Keuangan (PMK) mengenai pajak UMKM. Sejak tanggal 1 Juli 2018 pemerintah mengeluarkan peraturan tentang tarip baru PPh Final untuk UMKM, awalnya UMKM dikenakan pajak sebesar $1 \%$, tapi sekarang dipangkas menjadi $0,5 \%$ tidak berlaku bagi seluruh pengusaha UMKM. Adapun dari ketentuan dan peraturan yang cukup meringankan PP tersebut berlaku bagi pelaku usaha UMKM yang omzetnya dan peredaran asetnya kurang dari 4,8 $\mathrm{M}$ dalam satu tahun. Berdasarkan informasi yang dihimpun oleh DJP Kemenkeu, kegiatan atau usaha tersebut meliputi kegaiatan perdagangan, kegaiatan industri, dan jasa seperti misalnya toko/kios/kios kelontong, pakaian, elektronik, bengkel, penjahit, warung/rumah makan, salon, dan usaha lainnya (Sumarsan, 2015)

UMKM berdasarkan Undang Undang Nomor 20 Tahun 2008 tentang UMKM (Usaha Mikro Kecil dan Menegah) (Mattalatta \& Nugroho, 2017) adalah usaha atau ikhtiar produktif milik orang perorangan dan atau badan usaha perorangan yang memenuhi syarat atau kriteria sebagaimana diatur dalam Undang-Undang. Usaha 
kecil adalah usaha atau proses bisnis yang aktif serta produktif dan berdiri sendiri, yang dilakukan oleh oleh orang per orang atau badan usaha yang bukan merupakan perusahaan atau bukan cabang perusahaan yang dimiliki atau dikuasai menjadi bagian baik langsung ataupun tidak langsung dari usaha menengah atau usaha besar yang memenuhi kriteria usaha kecil sebagaimana dimaksud alam Undang Undang ini. Badan Pusat Statistik (BPS) mengelompokkan UMKM berdasarkan jumlah tenaga kerja. Usaha yang memiliki 1-4 orang staf atau karyawan dikelompokkan sebagai usaha mikro, 5-19 orang tenaga kerja sebagai usaha kecil, 20-99 orang tenaga kerja sebagai usaha menengah dan bila mencapai 100 orang tenaga kerja atau lebih digolongkan sebagai usaha besar (Syafik \& Arif, 2020).

\section{Kesadaran Wajib Pajak}

Kesadaran adalah unsur dalam diri manusia untuk memahami realitas dan bagaimana mereka bertindak atau bersikap terhadap realitas. (Winatapura et al., 2019). menjelaskan bahwa kesadaran adalah keadaan mengetahui atau mengerti. Kesadaran wajib pajak akan perpajakan adalah rasa yang timbul dari dalam diri Wajib Pajak atas kewajibannya membayar pajak dengan ikhlas tanpa adanya unsur paksaan. Dengan kesadaran pajak yang tinggi, kepatuhan wajib pajak terhadap kewajiban pajaknya dapat meningkat. Hal tersebut sejalan dengan penelitian (Suardana, 2014) bahwa kesadaran Wajib Pajak memiliki pengaruh terhadap kepatuhan Wajib Pajak.

(Irianto, 2005) menjelaskan beberapa bentuk kesadaran membayar pajak yang mendorong wajib pajak untuk membayar pajak. Pertama, kesadaran bahwa pajak merupakan bentuk partisipasi dalam menunjang pembangunan negara. Dengan menyadari hal ini, wajib pajak mau membayar pajak karena merasa tidak dirugikan dari pemungutan pajak yang dilakukan. Pajak disadari digunakan untuk pembangunan negara guna meningkatkan kesejahteraan warga negara. Kedua, kesadaran bahwa penundaan pembayaran pajak sangat merugikan negara. Wajib pajak mau membayar pajak karena memahami bahwa penundaan pajak berdampak pada kurangnya sumber daya finansial yang dapat mengakibatkan terhambatnya pembangunan negara. Ketiga, kesadaran bahwa pajak ditetapkan dengan UndangUndang dan dapat dipaksakan. Wajib pajak akan membayar karena pembayaran pajak disadari memiliki landasan hukum yang kuat dan merupakan kewajiban mutlak setiap warga negara.

\section{Sanksi Pajak dan Kepatuhan Wajib Pajak}

Sanksi adalah suatu tindakan berupa hukuman yang diberikan kepada orang yang melanggar peraturan. Peraturan atau Undang-Undang merupakan ramburambu bagi seseorang untuk melakukan sesuatu mengenai apa yang harus dilakukan dan apa yang seharusnya tidak dilakukan. Sanksi diperlukan agar peraturan atau Undang-Undang tidak dilanggar. Sanksi pajak merupakan jaminan bahwa peraturan perundang-undangan perpajakan (norma perpajakan) akan ditaati, dengan kata lain sanksi perpajakan merupakan alat pencegah agar wajib pajak tidak melanggar norma perpajakan menganggap remeh dengan denda yang kecil (Lovihan, 2014). 
Dalam Kamus Umum Bahasa Indonesia, kepatuhan berarti tunduk atau patuh pada ajaran atau aturan (Kemendikbud, 2020). Sedangkan menurut Gibran (2015) dalam (Nurul, 2013) sebagaimana yang dikutip oleh (Lovihan, 2014) kepatuhan adalah motivasi seseorang, kelompok atau organisasi untuk berbuat atau tidak berbuat sesuai dengan aturan yang ditetapkan. Dalam pajak, aturan yang berlaku adalah Undang-Undang Perpajakan. Jadi, kepatuhan pajak merupakan kepatuhan seseorang, dalam hal ini adalah wajib pajak, terhadap peraturan atau UndangUndang Perpajakan. Wajib pajak yang patuh adalah wajib pajak yang taat memenuhi serta melaksanakan kewajiban perpajakan sesuai dengan peraturan perundang-undangan perpajakan (Rahayu, 2010).

\section{B. METODE PENELITIAN}

Penelitian ini bertujuan untuk meninjau factor-faktor apa saja yang mempengaruhi kesadaran wajib pajak terhadap kepatuhan wajib pajak dalam membayar pajak, pemahaman dan pengetahuan perpajakan terhadap kepatuhan wajib pajak dalam membayar pajak, sanksi pajak terhadap wajib pajak dalam membayar pajak di Kecamatan Suralaga Kabupaten Lombok Timur dengan populasi sebanyak 171 orang pemilik UMKM dengan 80 responden yang di ambil dengan menggunakan metode Purposive sampling.

Metode penelitian yang digunakan adalah metode penelitian kuantitatif dengan analisis data sekunder yang memanfaatkan sumber data yang sudah ada dan mengolah data tersebut (Martono, 2010), obyek dalam penelitian dilaksanakan di Kecamatan Suralaga Lombok Timur. Variabel yang digunakan dalam penelitian ini adalah dua variabel, yaitu variabel dependen (pajak UMKM) dan independen (UMKM). Teknik mengumpulkan data menggunakan observasi dan quesioner, Pemberian skor atau penilaian dalam penelitian ini menggunakan skala Likert, yaitu metode yang mengukur sikap dengan menyatakan setuju atau tidak setujuan terhadap subyek, objek atau kejadian tertentu dengan menggunakan skor 1-5.

\section{HASIL DAN PEMBAHASAN}

Dari penyebaran instrument penelitian yang bejudul Faktor-Faktor Yang Mempengaruhi Kepatuhan Wajib Pajak Dalam Membayar Pajak UMKM Di Kecamatan Suralaga. Sampel atau Responden dalam penelitian ini sebanyak 80 yang diambil secara acak berasal dari 15 desa (Desa Tumbuh Mulia, Gerung Permai, Bagik Payung Timur, Paok Lombok, Tebaban, Bagik Payung, Bagik Payung Selatan, Anjani, Suralaga, Waringin, Kerongkong, Dames Damai, Dasan Borok, Bintang Rinjani dan Gapuk) yang tergolong dalam satu kecamatan yaitu kecamatan Suralaga memiliki karakteristik berdasarkan jenis kelamin, usia dan pendidikan terakhir. 


\section{Jenis Kelamin}

\section{Tabel 4.1}

\section{Karakteristik Responden Berdasarkan Jenis Kelamin}

\begin{tabular}{|c|c|c|c|}
\hline No & Jenis Kelamin & Jumlah & Persen \\
\hline 1. & Laki-Laki & 49 & 61,2 \\
\hline 2. & Perempuan & 31 & 38,8 \\
\hline & Total & 80 & 100 \\
\hline
\end{tabular}

Sumber: Data Primer

Dari Tabel 4.1 menunjukkan bahwa dari 80 orang responden yang berjenis kelamin laki-laki sebanyak $49(61,2 \%)$ orang dan perempuan berjumlah $31(38,8$ $\%$ ) orang.

\section{Umur}

Tabel 4.2

Karakteristik Responden Berdasarkan Umur

\begin{tabular}{|c|c|c|c|}
\hline No & Umur & Jumlah & Persen \\
\hline 1 & $20-29$ & 14 & 17.5 \\
\hline 2 & $30-39$ & 31 & 38,8 \\
\hline 3 & $40-40$ & 31 & 38,8 \\
\hline 4 & $50-59$ & 4 & 5,0 \\
\hline \multicolumn{2}{|c|}{ Total } & 80 & 100 \\
\hline
\end{tabular}

Dari Tabel 4.2 menunjukkan bahwa dari 80 orang responden yang berumur 20-29 sebanyak $14(17,5 \%)$ orang, 30-39 sebanyak 31 (38,8\%) orang, 40-49 sebanyak 31 (31\%) orang dan 50-59 sebanyak $4(5,0 \%)$ orang.

\section{Pendidikan Terakhir}

Tabel 4.3

Karakteristik Responden Berdasarkan Pendidikan Terakhir

\begin{tabular}{cccc}
\hline No & Pendidikan & Jumlah & Persen \\
\hline 1 & SD & 4 & 5,0 \\
2 & SMP & 6 & 7,5 \\
3 & SMA & 40 & 50,0 \\
4 & S1 & 28 & 35,0 \\
5 & S2 & 2 & 2,5 \\
\hline \multicolumn{4}{c}{ Total } \\
\multicolumn{4}{c}{ Sumber: Data Primer }
\end{tabular}

\section{Pengujian Persyaratan Hipotesis}

Uji yang dilakukan dalam penelitian ini adalah Uji Reliabilitas Instrumen yang terdiri dari variabel independen dan dependen atau variabel terikat dan variabel bebas. Untuk menguji penelitian ini menggunakan SPSS versi 16. Hasil dari penelitian ini didapatkan nilai Alpha atau $r_{\text {hitung }}$ dari variabel X sebesar $(0,857)$ yang artinya lebih besar dari $r_{\text {tabel }}$ sebesar $(0,217)$ yang dapat diinterpretasikan bahwa seluruh item kuesioner variabel $\mathrm{X}$ reliabel, serta didapatkan nilai Alpha atau 


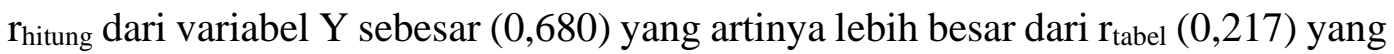
dapat diinterpretasikan bahwa seluruh item kuesioner variabel Y reliabel.

\section{Uji Validitas Instrumen}

Untuk mengukur tingkat validitas instrumen, penelitian ini menggunakan rumus korelasi product moment pada SPSS versi 16. Dalam hal ini masing-masing item yang ada di variabel $\mathrm{X}$ dan $\mathrm{Y}$ akan di uji korelasinya dengan skor total variabel tersebut kemudian dibandingkan dengan nilai $r_{\text {hitung. Hasil Uji Validitas Instrument }}$ Variabel Independen (X) dan Variabel Dependen (Y) didapatkan nilai dari sampel $(\mathrm{N})=80$ sebesar 0,217. Merujuk pada hasil dari semua instrument untuk variabel $\mathrm{X}$ (Kesadaran membayar pajak, pengetahuan dan pemahaman membayar pajak, sanksi pajak) yang terdiri dari 17 item pernyataan semuanya menghasilkan nilai $r_{\text {hitung }}>r_{\text {tabel }}$. Selain itu variabel Y (kepatuhan wajib pajak) yang terdiri dari 5 item pernyataan semuanya menghasilkan nilai $r_{h i t u n g}>r_{\text {tabel }}$. Sehingga dapat disimpulkan bahwa semua instrument dalam penelitian ini dapat dikatakan valid. Untuk hasil uji normalitas menggunakan SPSS versi 16, diketahui nilai signifikansi 0,164>0,05, maka dapat disimpulkan nilai residual berdistribusi normal. Sedangkan dari hasil uji hipotesis didapatkan hasil bahwa Kesadaran wajib pajak berpengaruh terhadap kepatuhan wajib pajak. Sedangkan Pemahaman dan pengetahuan perpajakan berpengaruh terhadap kepatuhan wajib pajak. Selain itu, Sanksi pajak berpengaruh terhadap kepatuhan wajib pajak.

\section{Pembahasan Hasil Penelitian}

\section{Pengaruh Kesadaran Wajib Pajak Terhadap Kepatuhan Wajib Pajak Dalam Membayar Pajak.}

Berdasarkan hasil penelitian yang didapatkan bahwa kesadaran wajib pajak berpengaruh terhadap wajib pajak, hal tersebut dibuktikan dengan hasil pengujian statistik menggunakan pengujian $t_{\text {test }}$ dengan hasil $t_{\text {hitung }}=(3,716)>t_{\text {tabel }}=(1,991)$.

Hal ini membuktikan bahwa kesadaran merupakan unsur dalam diri manusia untuk memahami realitas dan bagaimana mereka bertindak atau bersikap terhadap realitas. Dengan kesadaran pajak yang tinggi, kepatuhan wajib pajak terhadap kewajiban pajaknya dapat meningkat. Hal tersebut sejalan dengan penelitian (Suardana, 2014) bahwa kesadaran Wajib Pajak memiliki pengaruh terhadap kepatuhan Wajib Pajak.

\section{Pengaruh Pemahaman Dan Pengetahuan Perpajakan Terhadap Kepatuhan Wajib Pajak Dalam Membayar Pajak.}

Dari hasil analisa pada lampiran, didapakan hasil $t_{\text {hitung }}>\mathrm{t}_{\text {tabel }}$ yang diinterpretasikan sebagai pengetahuan tentang perpajakan memiliki pengaruh terhadap kepatuhan wajib pajak, pemahaman menjadi salah satu faktor yang berpengaruh dalam kepatuhan wajib pajak.

Pemahaman dapat diartikan sebagai proses, perbuatan, cara memahami atau memahamkan. Wajib pajak yang tidak memahami peraturan perpajakan secara jelas cenderung akan menjadi wajib pajak yang tidak taat. Jelas bahwa semakin paham wajib pajak terhadap peraturan perpajakan, maka semakin paham pula wajib pajak 
terhadap sanksi yang akan diterima bila melalaikan kewajiban perpajakan mereka. Hal tersebut didukung oleh hasil penelitian yang dilakukan oleh (Ningtyas \& Cahaya, 2012) yang berpendapat bahwa pemahaman perpajakan mempengaruhi kepatuhan Wajib Pajak pemilik UMKM. Berdasarkan hal tersebut dapat dikatakan bahwa dengan meningkatnya pemahaman perpajakan Wajib Pajak maka kepatuhan Wajib Pajak akan meningkat juga.

\section{Pengaruh Sanksi Pajak Terhadap Kepatuhan Wajib Pajak Dalam Membayar Pajak.}

Berdasarkan hasil pengujian hipotesis ketiga menyatakan bahwa pemahaman perpajakan secara parsial berpengaruh signifikan terhadap kepatuhan Wajib Pajak. Hasil Uji t diperoleh nilai thitung sebesar 4,057 dan p-value sebesar 0,000. Ini menunjukkan bahwa sanksi merupakan variabel yang memengaruhi seseorang untuk mematuhi wajib pajak dalam membayar pajak. Hal tersebut sesuai dengan penelitian yang dilakukan oleh (Rama, 2020) bahwa sanksi pajak berpengaruh terhadap kepatuhan dalam membayar pajak, hal tersebut dikarenakan sanksi merupakan hukuman negatif terhadap seseorang yang melanggar perarturan.

\section{SIMPULAN}

Berdasarkan dari data yang telah dikumpulkan terhadap permasalahan dengan menggunakan pendekatan kuantitatif dengan uji statistik uji t, maka dapat diambil kesimpulan sebagai berikut: tingkat kesadaran wajib pajak berpengaruh secara signifikan terhadap kepatuhan wajib pajak pada sektor UMKM. Penelitian ini didukung oleh hasil penelitian (Prawagis et al., 2016) menunjukkan bahwa kesadaran membayar pajak, pengetahuan dan pemahaman atas mekanisme pembayaran pajak dan sanksi pajak berpengaruh signifikan baik secara simultan maupun parsial. Pengetahuan dan pemahaman perpengaruh secara signifikan terhadap kepatuhan wajib pajak pada sektor UMKM. Hasil penelitian ini sejalan dengan penelitian yang dilakukan oleh (Tene et al., 2017). Sanksi pajak berpengaruh secara signifikan terhadap kepatuhan wajib pajak pada sektor UMKM. Hasil penelitian ini didukung oleh penelitian yang dilakukan oleh (Hendra Hutabarat et al., 2018). Kepatuhan wajib pajak, pengetahuan dan pemahaman, sanksi, berpengaruh secara signifikan terhadap kepatuhan wajib pajak pada sektor UMKM. Hasil penelitian tersebut signifikan dengan penelitian yang dilakukan oleh (Rama, 2020) 


\section{DAFTAR PUSTAKA}

Aliffia, A. (2019). Pajak Sebagai Sumber Pendapatan Utama Negara Indonesia. Https://Unjkita.Com/Pajak-Sebagai-Sumber-Pendapatan-Utama-NegaraIndonesia/.

Djaman, L. S. (2018, Juni 8). Peraturan Pemerintah No. 23 Tahun 2018 Tentang Pajak Penghasilan Atas Penghasilan dari Usaha yang Diterima atau Diperoleh Wajib Pajak yang Memiliki Peredaran Bruto Tertentu. (M. H. Indonesia, Producer) Retrieved 2020, from Direktorat Jenderal Pajak: https://www.pajak.go.id/id/peraturan-pemerintah-nomor-23-tahun-2018

Hendra Hutabarat, R., Ratnawati, V., \& Julita. (2018). FAKTOR-FAKTOR YANG MEMPENGARUHI KEMAUAN UNTUK MEMBAYAR PAJAK WAJIB PAJAK ORANG PRIBADI YANG MELAKUKAN PEKERJAAN BEBAS DI KOTA PEKANBARU. JURNAL EKONOMI, 26(1), 16-28. https://doi.org/10.31258/JE.26.1.P.16-28

Huda, A., Basri, Y. M., \& Julita. (2016). PENGARUH PERSEPSI ATAS EFEKTIFITAS SISTEM PERPAJAKAN, KEPERCAYAAN, TARIF PAJAK DAN KEMANFAATAN NPWP TERHADAP KEPATUHAN MEMBAYAR PAJAK (STUDI EMPIRIS PADA WAJIB PAJAK UMKM MAKANAN DI KPP PRATAMA PEKANBARU SENAPELAN). Jurnal Online Mahasiswa (JOM) Bidang Ilmu Ekonomi, 2(2), 1-15. www.rri.co.id

Irianto. (2005). Politik Perpajakan. Yogyakarta: UII Press.

Kemendikbud, B. P. dan P. B. R. I. (2020). Lema “Kepatuhan”- Tesaurus Tematis Bahasa Indonesia. http://tesaurus.kemdikbud.go.id/tematis/lema/kepatuhan

Lovihan, S. (2014). Pengaruh Kesadaran Membayar Pajak, Pengetahuan dan Pemahaman Peraturan Perpajakan, dan Kualitas Layanan terhadap Kemauan Membayar Pajak Wajib Orang Pribadi di Kota Tomohon. JURNAL RISET AKUNTANSI DAN AUDITING “GOODWILL," 5(1), 44-59. https://doi.org/10.35800/jjs.v5i1.4930

Martono, N. (2010). Metode Penelitian Kuantitatif: Analisis Isi dan Analisis Data Sekunder (S. P. T. Utami (ed.); 2nd ed.). Rajawali Pers. https://onesearch.id/Record/IOS1.INLIS000000000398558\#description

Mattalatta, A., \& Nugroho, S. S. (2017, April 3). Undang-Undang Nomor 20 Tahun 2008 Tentang Usaha Mikro, Kecil, dan Menengah. (Otoritas Jasa Keuangan) Retrieved 2020, from Otoritas Jasa Keuangan: https://www.ojk.go.id/sustainable-finance/id/peraturan/Undang-

Undang/Documents/Undang-

Undang\%20Nomor\%2020\%20Tahun\%202008\%20Tentang\%20Usaha\%20

Mikro,\%20Kecil,\%20dan\%20Menengah.pdf

Mory, S. (2015). Pegaruh Pelayanan Fiskus, Sanksi Perpajakan, Sosialisasi Perpajakan, Kesadaran Wajib Pajak dan Kondisi Keuangan Terhadap Kepatuhan Wajib Pajak (Studi pada Wajib Pajak Orang Pribadi yang Melakukan Kegiatan Usaha dan Pekerjaan Bebas di KPP Pratama Tanjung B. 
Jurnal Akuntansi Fakultas Ekonomi Universitas Maritim Raja Ali Haji, 120. http://jurnal.umrah.ac.id/?s=setia+mory

Ningtyas, \& Cahaya, R. P. (2012). Pengaruh Pemahaman Perpajakan, Tarif Pajak, Sanksi, Serta Pelayanan Pembayaran Terhadap Kepatuhan Wajib Pajak UMKM Di Kota Malang. Universitas Brawijaya, Fakultas Ekonomi dan Bisnis Program Studi Akuntansi. Malang: Universitas Braiwijaya. Retrieved from http://repository.ub.ac.id/id/eprint/105910

Nurul, mas'ud waqiah. (2013). Tingkat kepatuhan wajib pajak orang pribadi dalam membayar dan melaporkan kewajiban perpajakan. Persepsi Masyarakat Terhadap Perawatan Ortodontik Yang Dilakukan Oleh Pihak Non Profesional, 53(9), 1689-1699.

Prameswari, I. G. (2019, November). Penerapan E-System Perpajakan. p. Pajakku.com. Retrieved Mei 2020, from Pajakku.com.

Prawagis, F. D., Zahroh ZA, ., \& Mayowan, Y. (2016). PENGARUH PEMAHAMAN ATAS MEKANISME PEMBAYARAN PAJAK, PERSEPSI TARIF PAJAK DAN SANKSI PAJAK TERHADAP KEPATUHAN WAJIB PAJAK UMKM (Studi Pada Wajib Pajak Yang Terdaftar di KPP Pratama Batu). Jurnal Mahasiswa Perpajakan (JEJAK), $10(1)$, $1-8$. http://perpajakan.studentjournal.ub.ac.id/index.php/perpajakan/article/view/ 293

Rahayu, S. K. (2010). Perpajakan Indonesia: Konsep dan Aspek Formal (1 ed.). Yogyakarta, Jawa Tengah, Indonesia: Graha Ilmu. Retrieved from http://disperpusip.jatimprov.go.id/inlis/opac/detail-opac?id=30935

Rama, M. (2020). FAKTOR-FAKTOR YANG MEMPENGARUHI KEPATUUHAN WAJIB PAJAK USAHA MIKRO KECIL DAN MENENGAH (UMKM) DALAM MEMBAYAR PAJAK SESUAI PP NO. 23 TAHUN 2018 PADA UMKM DI KABUPATEN INDRAGIRI HILIR (INHIL). Universitas Islam Negeri Sultan Syarif Kasim, Fakultas Ekonomi dan Ilmu Sosial; Program Studi AKuntansi. Riau: Universitas Islam Negeri Sultan Syarif Kasim. Retrieved 2020, from http://repository.uin-suska.ac.id/id/eprint/25650

Republik Indonesia, M. H. dan H. A. M., \& Syamsudin, A. (2013, June 13). PERATURAN PEMERINTAH REPUBLIK INDONESIA No 46 TAHUN 2013 Tentang PAJAK PENGHASILAN ATAS PENGHASILAN DARI USAHA YANG DITERIMA ATAU DIPEROLEH WAJIB PAJAK YANG MEMILIKI PEREDARAN BRUTO TERTENTU. https://www.pajak.go.id/sites/default/files/2019-05/PP Nomor 46 Tahun 2013.pdf

Seni, N. N., \& Ratnadi, N. D. (2017). THEORY OF PLANNED BEHAVIOR UNTUK MEMPREDIKSI NIAT BERINVESTASI. E-Jurnal Ekonomi dan Bisnis Universitas Udayana, 6(12), 4043-4068. doi:https://doi.org/10.24843/EEB.2017.v06.i12.p01 
Suardana. (2014). Pengaruh Kesadaran Wajib Pajak, Sosialisasi Perpajakan, Kualitas Pelayanan Pada Kepatuhan Wajib Pajak. E-Jurnal Akuntansi Universitas Udayana, 340-353.

Sumarsan, T. (2015). Perpajakan Indonesia (4 ed.). Jakarta Barat, DKI Jakarta, Indonesia: Indeks.

Syafik, M., \& Arif, R. (2020). ANALISIS FAKTOR - FAKTOR YANG BERPENGARUH TERHADAP KESADARAN KEWAJIBAN PERPAJAKAN PADA SEKTOR USAHA KECIL DAN MENENGAH (UKM). Media Mahardhika, $18(2), \quad 300$. https://doi.org/10.29062/mahardika.v18i2.160

Tene, J. H., Sondakh, J. J., \& Warongan, J. D. L. (2017). PENGARUH PEMAHAMAN WAJIB PAJAK, KESADARAN PAJAK, SANKSI PERPAJAKAN DAN PELAYANAN FISKUS TERHADAP KEPATUHAN WAJIB PAJAK. Jurnal EMBA: Jurnal Riset Ekonomi, Manajemen, Bisnis Dan Akuntansi, 5(2), 443-453. https://ejournal.unsrat.ac.id/index.php/emba/article/view/15702

Winatapura, D. S., Deswita, Fisli, A., \& Adi, W. A. (2019). Mechanosynthesis, crystal structure, magnetic and absorption properties of Al substituted $\mathrm{BaFe}<$ inf $>12</$ inf $>\mathrm{O}<\mathrm{inf}>19</$ inf $>$. Jurnal Teknologi, 81(5). https://doi.org/10.11113/jt.v81.13567

Yadnyana, I. K., \& Sudiksa, I. B. (2011). Pengaruh Peraturan Pajak Serta Sikap Wajib Pajak Terhadap Kepatuhan Wajib Pajak Koperasi di Kota Denpasar. Jurnal Akutansi, 17(2), 197-206.

Yusro, H. W., \& Kiswanto. (2014, November). PENGARUH TARIF PAJAK, MEKANISME PEMBAYARAN PAJAK DAN KESADARAN MEMBAYAR PAJAK TERHADAP KEPATUHAN WAJIB PAJAK UMKM DI KABUPEN JEPARA. Accounting Analysis Journal, 3(4), 429436. doi:https://doi.org/10.15294/aaj.v3i4.4201 